\title{
Sample Size Calculation for Animal Studies Using Degree of Freedom (E); an Easy and Statistically Defined Approach for Metabolomics and Genetic Research
}

\author{
Ilyas $\mathrm{MN}^{1}$, Adzim $\mathrm{MKR}^{2}$, Simbak $\mathrm{NB}^{1}$ and Atif $\mathrm{AB}^{1 *}$ \\ ${ }^{1}$ Faculty of Medicine, Universiti Sultan Zainal Abidin, Malaysia \\ ${ }^{2}$ Faculty of Health Sciences, Universiti Sultan Zainal Abidin, Malaysia
}

Submission: November 01, 2017; Published: December 06, 2017

*Corresponding author: Atif AB, Faculty of Medicine, Universiti Sultan Zainal Abidin, Malaysia, Tel: 006096275646; Email: atifamin@unisza.edu.my

\section{Opinion}

Sample size calculation is the primary vital step of experimental and preclinical/toxicology studies in animals. Total number of animals to include in experiment or trial is the key question for young researchers. The recruitment and determination of animal numbers in experiments are critical to evaluate cost effectiveness of study and inclusion prerequisites are essential to attain sufficient statistical power of test and for findings for variations among factors under study [1].

To find how many animal we should include in our study is the most confusing decision for young researchers. The use of too small number of animals will lead to lack of real experimental statistical significance or will miss the novel findings and too many numbers of animals will lead to waste of money, resources, time and ethical issues [2,3]. Sample size calculation from statistical point of view is very confusing and difficult to understand for researchers, but reliability of statistical calculation is much higher than simple sample size calculation based on crude methods. The problem of sample size for clinical studies has been explained well and almost solved with many solutions for researchers. Still animal numbers justification is a problem for young scientists and not explored well in literature yet.

The aim of our article is to provide brief explanation about animal sample size calculation methods and to suggest an easy approach to justify animal numbers in clinical studies. Before, we explain about sample size calculation methods, we should know about the term power of study. The power of study means, the probability that it can detect a treatment effect, if it is present during an experiment. In animal studies six factors are very important to find cause effect relationship.
Among these factors are:
a) Power of study
b) Sample size
c) Inter-individual variability
d) The magnitude of response to treatment
e) The significance level
f) Alternative hypotheses

Apart from all above assumptions in animal studies power and sample size are very important to define strength of an experimental effect. Fixed number of animals in groups estimates the power of study, because by assuming alpha and estimation of significance level defines association within groups. There are several methods used for sample size calculation based on type of variables (dichotomous or continuous or time to occurrence of an event) and depends upon the type of study [4]. In animal studies, hypotheses testing is based on variables like dichotomous variable, as yes-no response or outcome such as occurrence of disease or survival at given time; continuous variable like physiological function, as measuring blood flow or urine output; and time to occurrence of an event, prediction of death or disease [5].

Generally, few factors should be under consideration or estimated to determine sample size. Sample size calculation for animal studies estimation factors includes: the effect size (difference between two groups), standard deviation (to see variability of population within the sample), significance level (alpha or type-I error), power (probability of finding an effect), direction of an effect (one-tailed or two-tailed), statistical tests 
and attrition or expected deaths $(10 \%$ or $20 \%$ depends upon experiment) $[2,3,5]$. Therefore, power analysis uses these all factors to calculate sample size. To avoid complex statistical calculations, two methods are widely used for animal studies. The power analysis and a simple approach (crude methods) $[2,6,7]$. Besides these, other online tools are available like $G^{*}$ power software and online tools to estimate sample size in animal studies $[2,8]$.

Our article suggests a simple approach to calculate sample size for new researcher to avoid statistical confusions and ethical issues. This method is based on law of diminishing return and equation, called as "resource equation" $[2,9,10]$. This method is suitable for novel studies and young researcher who do not have previous available literature to estimate factors for power analysis. This method is used when effect size, standard deviation are impossible to measure because no previous findings are available. It is also suitable for researchers, who are only interested in the findings or effect. The best thing about this method is ease of use, simple calculations and not requiring hypothesis testing and statistical analysis.

This method is based on ANOVA calculations and has "E" value which is called the degree of freedom which must be between 10 and 20. If the E value is less than 10 then you should increase number of animals and if $E$ value is more than 20 then $\mathrm{u}$ have sufficient animals for your experiment. Any sample size having E value between 10 and 20 is considered enough. E value can be calculated by following equation,

\section{$\mathrm{E}=$ Total number of animals - Total number of groups}

Let's see the example, suppose a researcher wants to see drug effect and he made 6 groups (five groups depends on different doses of drug and one control group) with 6 rats each. So, in this case

$$
E=(6 \times 6)-6
$$

\section{$E=36-6=30$}

Value of $\mathrm{E}$ in this case is 30 , which is more than 20; hence sample size in this case is more than enough. If sample size is 4 in each group the E value will be 18 and that is acceptable according to range of E. Although, this method is based on ANOVA and degree of freedom is acceptable for all experiments. So, we concluded that the easiest method to calculate the sample size for the people with least knowledge is using degree of freedom. Though few statistical rigours could be there in advance analysis but still this method could be the method of choice.

\section{References}

1. Blaise BJ (2013) Data-driven sample size determination for metabolic phenotyping studies. Anal Chem 85(19): 8943-8950.

2. Charan J, Kantharia N (2013) How to calculate sample size in animal studies? J Pharmacol Pharmacother 4(4): 303-306.

3. Fitts DA (2011) Ethics and animal numbers: informal analyses, uncertain sample sizes, inefficient replications, and type I errors. J Am Assoc Lab Anim Sci 50(4): 445-453.

4. Shah $\mathrm{H}$ (2011) How to calculate sample size in animal studies. National Journal of Physiology, Pharmacy and Pharma Cology 1(1): 35-39.

5. Dell RB, Holleran S, Ramakrishnan R (2002) Sample size determination. ILAR Journal 43(4): 207-213.

6. Cohen J (1988) Statistical analysis for the behavioral sciences. Hillsdale: Lawrance Erlbaum, USA.

7. Jones S, Carley S, Harrison M (2003) An introduction to power and sample size estimation. Emerg Med J 20(5): 453-458.

8. Faul F, Erdfelder E, Lang AG, Buchner A (2007) G* Power 3: A flexible statistical power analysis program for the social, behavioral, and biomedical sciences. Behav Res Methods 39(2): 175-191.

9. Festing MF (2006) Design and statistical methods in studies using animal models of development. ILAR J 47(1): 5-14.

10. Festing MF, Altman DG (2002) Guidelines for the design and statistical analysis of experiments using laboratory animals. ILAR Journal 43(4): 244-258.

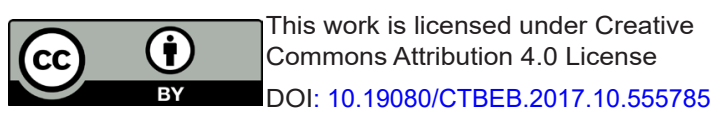

\begin{tabular}{|l|}
\hline Your next submission with Juniper Publishers \\
will reach you the below assets \\
- Quality Editorial service \\
- Swift Peer Review \\
- Reprints availability \\
- E-prints Service \\
- Manuscript Podcast for convenient understanding \\
- Global attainment for your research \\
- Manuscript accessibility in different formats \\
( Pdf, E-pub, Full Text, Audio) \\
- Unceasing customer service \\
Track the below URL for one-step submission \\
https://juniperpublishers.com/online-submission.php \\
\hline
\end{tabular}

